\title{
EFFECTS OF HEATING RATE ON THE MORTALITY OF LIGHTBROWN APPLE MOTH
}

\author{
S.L. ALDERSON, B.C. WADDELL and A.N. RYAN \\ HortResearch, Private Bag 92-169, Auckland
}

\begin{abstract}
The effect of heating rate on mortality of fifth instar Epiphyas postvittana (Walker) was investigated. Insects were treated in air or water ramped to target temperatures over a range of times. Hot air treatments where the temperature of the air was increased from 20 to $43^{\circ} \mathrm{C}$ in 1,2 and $4 \mathrm{~h}$ were associated with lethal times for $99 \%$ mortality $\left(\mathrm{LT}_{99}\right)$ that were 29.8, 45.8 and 44.6 minutes longer than the $\mathrm{LT}_{99}$ for LBAM exposed to air at $43^{\circ} \mathrm{C}$ throughout the treatment. In contrast, no increase in tolerance was observed if the insects were immersed in water which was heated to a target of $43^{\circ} \mathrm{C}$ over similar ramp durations. Keywords: lightbrown apple moth, Epiphyas postvittana, thermotolerance, heating rate.
\end{abstract}

\section{INTRODUCTION}

Heating as a quarantine treatment is a proven technology for a range of crops (Armstrong 1994; Waddell et al. 1997). Most heat treatments have been developed for tropical produce but research has also been carried out for temperate crops (Dentener et al. 1996; Neven et al. 1996; Yokoyama and Miller 1987). The recent thermal history of the insect has a significant effect on the efficacy of heat treatment protocols. For example, long exposure to elevated non-lethal temperatures may condition the insect to be more tolerant to subsequent treatment at lethal temperatures (Laidlaw et al. 1996). Both static (Beckett and Evans 1997; Lester and Greenwood 1997; Waddellet al. 1997) and ramped (Waddell et al. 1997) pretreatments can result in such conditioning.

When insects are heated inside fruit, the temperature experienced is effectively that of ramped heating. The details depend on the medium (air or water) temperature, the heat-transfer coefficient at the fruit-medium interface, thermal conductivity of the fruit (Armstrong 1994) and the location of the pest in the fruit. It is therefore important to determine how thermotolerance is altered when insects experience different thermal profiles.

The aim of this study was to assess possible effects of exposure of fifth instar LBAM to temperatures in the non-lethal range $\left(20-43^{\circ} \mathrm{C}\right)$, over various ramp durations, on expression of LBAM mortality after subsequent treatment at a static $43^{\circ} \mathrm{C}$ in both hot air and hot water.

\section{Insects}

\section{MATERIALS AND METHODS}

Fifth instar LBAM were obtained from a laboratory colony reared on an artificial diet (Singh 1983; Clare et al. 1987) at $20^{\circ} \mathrm{C}$, a photoperiod of $16: 8$ (L:D) h, and $60 \%$ RH. Approximately 30 larvae were placed in each plastic container with a stainless steel gauze lid and base as described by Jones et al. (1995).

\section{Hot water treatments}

Treatments were conducted in a waterbath system (Purbeck Limited, Auckland, N.Z.) consisting of four 25 litre water baths. Grant (Cambridge, U.K.) heater units (temperature accuracy $\pm 0.01^{\circ} \mathrm{C}$ ) on each bath were independently controlled by a laptop computer running Workbench PC for Windows data acquisition and control software (Strawberry Tree, Sunnyvale, California, U.S.A). Temperatures were verified for each trial using an electronic thermometer (Model RT200, Measurements Standards Laboratory of New Zealand, Industrial Research Limited, Wellington, N.Z.). 
At the beginning of a ramped trial, six or seven containers of insects were simultaneously immersed in a water bath at $20^{\circ} \mathrm{C}$, which was then heated to $43^{\circ} \mathrm{C}$ in $30,35,45,60,90,120$ or 240 minutes, and maintained at $43^{\circ} \mathrm{C}$ for the remainder of the trial. For static temperature trials six or seven containers were simultaneously immersed in a water bath at $43^{\circ} \mathrm{C}$ which was held at this temperature for the duration of the treatment. One or two containers were immersed in $20^{\circ} \mathrm{C}$ water in a second waterbath at the beginning of the treatment as a non-heated control. Individual containers were removed over a range of time intervals to allow determination of the actual time required to achieve $99 \%$ mortality $\left(\mathrm{LT}_{99}\right)$. These containers were hydrocooled in the $20^{\circ} \mathrm{C}$ waterbath for 2 minutes and allowed to drain. Non-heated controls were removed after a period equivalent to the longest hot water immersion in each ramp trial including two minutes hydrocooling. All containers were stored in air at $20^{\circ} \mathrm{C}$ overnight before assessment. Each ramp trial was replicated at least four times.

\section{Hot air treatments}

Air treatments were carried out in the High Air Flow Controlled Atmosphere and Temperature (HAFCAT) fruit treatment facility (Dentener et al. 1996). Air velocity was set at $9 \mathrm{~m} / \mathrm{s}$, initial air temperature to $20^{\circ} \mathrm{C}$ and relative humidity to $85 \%$. Between eight and ten containers of insects were placed in a single drawer for each treatment. One or two containers were kept at ambient temperature to act as non-heated controls. Ramping trials, where temperature was increased from 20 to $43^{\circ} \mathrm{C}$ over 60,120 or 240 minutes and subsequently maintained at $43^{\circ} \mathrm{C}$, and static trials, where the temperature was maintained at $43^{\circ} \mathrm{C}$ throughout the treatment, were carried out. Individual containers were removed from the HAFCAT unit at intervals to allow determination of $\mathrm{LT}_{99} \mathrm{~S}$ for each treatment. All containers were held overnight at $20^{\circ} \mathrm{C}$ prior to mortality assessment. Six replicates of the static trial and four or five replicates of each ramped trial were carried out.

\section{Mortality assessment}

A binocular microscope ( $10 \mathrm{x}$ magnification) was used while assessing mortality of insects. Each insect was prodded with a pin several times. Insects that moved were recorded as live whilst those which did not were recorded as dead.

\section{Statistical analyses}

Analyses of individual treatments used the model:

$$
\log (-\log (1-p))=a+b t
$$

where $p=$ expected mortality and $t=$ time in minutes (Preisler and Robertson 1989). This gave approximate linearity and determined the estimated time for $99 \%$ mortality $\left(\mathrm{LT}_{99}\right)$. The $\mathrm{LT}_{99}$ was designed to give a mortality of:

$$
c+(1-c) 0.99 \text {, }
$$

where $c$ was the control mortality. $\mathrm{LT}_{99} \mathrm{~S}$ calculated are exclusive of the ramp period of the treatment.

The model was fitted using a robust version of the generalised linear model analysis available in S-PLUS (Chambers and Hastie 1991). This assumed that variance was proportional to that of a binomial distribution. The robust version reduced the weight given to points lying away from the main body of the data.

Error bars shown in Figures 1 and 2 represent 95\% confidence limits. Estimates of $\mathrm{LT}_{99}$ were compared using overlap of $95 \%$ confidence limits. Non overlap of $95 \%$ confidence limits is equivalent to a test for difference at approximately $\mathrm{P}=0.01$. Use of the $1 \%$ significance level in place of the $5 \%$ significance level provides a safeguard against finding too many significant differences. The safeguard is comparable to that provided by the formal use of a multiple comparison test.

\section{Hot water treatments}

\section{RESULTS}

No increase in tolerance with increasing ramp duration was observed in the hot water treatments (Figure 1). Static trials at $43^{\circ} \mathrm{C}$ resulted in an $\mathrm{LT}_{99}$ of $21.3(95 \%$ confidence limits; 16.5-27.5) minutes. Ramped trials did not produce significantly longer $\mathrm{LT}_{99}$ s than the static trials; 30.6, 30.8, 31.7, 29.3, 29.9 and 15 minutes for 30, 35, 45, 60, 90 and 120 minute ramps respectively. Considerable mortality occurred during 
the 120 minute ramp $(31.3-80 \%)$ before the target temperature was reached. This explains the lower $\mathrm{LT}_{99}$ for this ramp duration. $\mathrm{LT}_{99} \mathrm{~S}$ for 240 minute ramp trials could not be calculated as complete mortality was attained prior to completion of the ramp.

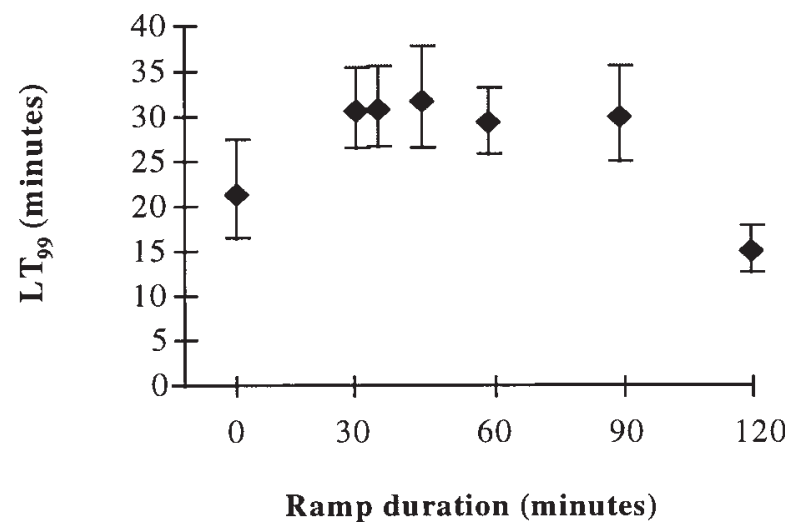

FIGURE 1: Mean $\mathbf{L T}_{99}$ of fifth instar light brown apple moth heated in water from $20-43^{\circ} \mathrm{C}$ over ramp durations of $0,30,35,45,60,90$ or 120 minutes. Vertical bars are $95 \%$ confidence limits on the mean of at least four replicates.

\section{Hot air treatments}

Static trials using the HAFCAT facility at $43^{\circ} \mathrm{C}$ produced an $\mathrm{LT}_{99}$ of $104(95 \%$ confidence limits; 97.7 - 110.7) minutes (Figure 2). Ramping the temperature from 20 to $43^{\circ} \mathrm{C}$ conferred thermotolerance on the insects with ramped trials exhibiting longer $\mathrm{LT}_{99} \mathrm{~s}$ than the static $43^{\circ} \mathrm{C}$ trial. $\mathrm{LT}_{99} \mathrm{~s}$ for the 60,120 and 240 minute ramps were not significantly different from each other suggesting that thermotolerance does not increase with ramp duration. On average the mean $\mathrm{LT}_{99}$ of ramped trials was $38.5 \%$ longer than the non-ramped $\mathrm{LT}_{99}$.

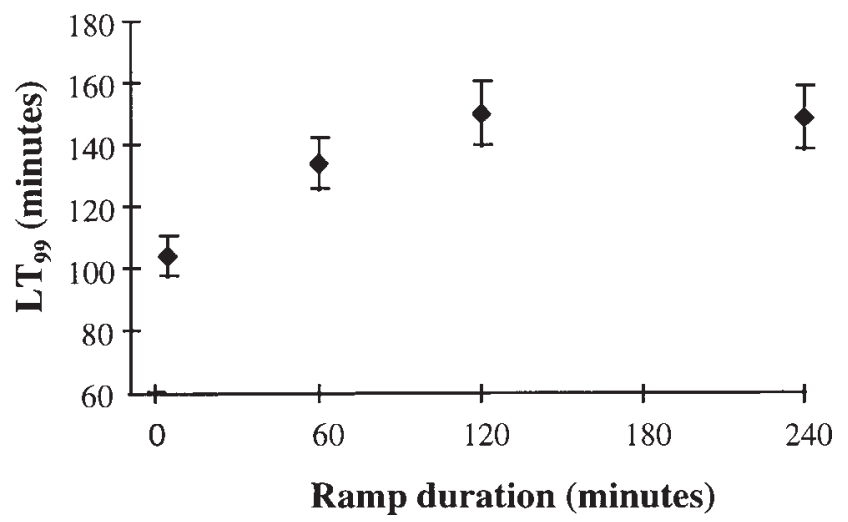

FIGURE 2: Mean $\mathrm{LT}_{99}$ of fifth instar light brown apple moth heated in air from 20$43^{\circ} \mathrm{C}$ over ramp durations of $0,60,120,180$ or 240 minutes. Vertical bars are $95 \%$ confidence limits on the mean of at least four replicates. 


\section{DISCUSSION}

Lester and Greenwood (1997) and Beckett and Evans (1997) reported thermotolerance of LBAM when static hot air pretreatments were followed by hot water immersion. Our research indicates that thermotolerance is also induced during ramped hot air treatments. Neven et al. (1996), using moist and vapour forced air, also observed thermotolerance with codling moth larvae which increased tolerance to temperature extremes if slower heating rates were used. Research in which insects were heated in air-filled vials in water (Neven 1998) also produced evidence of thermotolerance. These findings are in contrast to the results we observed when both the ramp and static components of the treatment occurred in hot water, in which case no evidence of thermotolerance was found. This suggests that the medium in which heating takes place may be important. Oxygen availability to insects may be restricted when heating takes place in water, perhaps explaining the lack of thermotolerance under these conditions. Yocum and Denlinger (1994) reported that thermotolerance induced by previous exposure to high temperatures can be reduced or eliminated by anoxia and suggested that physiological processes generating tolerance can only proceed under aerobic conditions. Insects heated to $40^{\circ} \mathrm{C}$ for varying ramp times under controlled atmosphere conditions $\left(1 \% \mathrm{O}_{2}, 1 \% \mathrm{CO}_{2}\right)$ did not exhibit thermotolerance (Whiting and Hoy 1998), supporting this conjecture.

Klein and Lurie (1992) suggested that slower heating rates during hot air treatments maintain apple quality compared with fast rates. However, insect tolerance of hot air treatment appears to be enhanced by these slower rates. It is likely that the extent of thermotolerance will vary between insect species and that ramping will affect various commodities differently. Ramping rate and medium are important factors which should be considered, together with time and temperature, when defining disinfestation treatments.

\section{ACKNOWLEDGEMENTS}

We thank A.M. Barrington for insect supply, M.J. Miller and P.G. Connolly for statistical analyses of data and the New Zealand Foundation for Research Science and Technology, contract number CO6644, for funding this project.

\section{REFERENCES}

Armstrong, J.W.,1994. Heat and cold treatments. Pp 102-120 In: Insect Pests and Fresh Horticultural Products: Treatments and Responses, R.E. Paull and J.W. Armstrong (Eds); CAB International.

Beckett, S.J. and Evans, D.E., 1997. The effects of thermal acclimation on immature mortality in the Queensland fruit fly Bactrocera tryoni and the lightbrown apple moth Epiphyas postvittana at a lethal temperature. Ent. Exp. et Applic. 82: 45-51.

Chambers, J.M. and Hastie, T.J., 1991. Statistical models in S. Wadsworth \& Brooks/ Cole, Pacific Grove, California.

Clare, G.K., Ochieng-Odera, J.P.R., Dalzell, S.J. and Singh, P. 1987. A practical rearing method for leafrollers (Lepidoptera: Tortricidae). N.Z .J. Zool. 14: 597-601.

Dentener, P.R., Alexander, S.M., Lester, P.J., Petry, R.J., Maindonald, J.H. and McDonald, R.M., 1996. Hot air treatment for disinfestation of lightbrown apple moth and longtailed mealy bug on persimmons. Postharv. Biol. Technol. 8: 143452.

Jones, V.M., Waddell, B.C. and Maindonald, J.H., 1995. Comparative mortality responses of three Tortricid (Lepidoptera) species to hot water. J. Econ. Ent. 88: 1356-1360.

Klein, J.D. and Lurie, S., 1992. Prestorage heat treatment for enhanced postharvest quality: interaction of time and temperature. HortSci. 27: 326-328.

Laidlaw, W.G., Armstrong, J.W., Chan, H.T. Jr. and Jang, E.B., 1996. The effect of temperature profile in heat-treated disinfestation on mortality of pests and on fruit quality. Pp 342-353 In: Proceedings of the International Conference on Tropical Fruits, Volume II, S. Vijaysengaran, M. Pauziah, M.S. Mohamed and S. Ahmad Tarmizi (Eds); Malaysian Agricultural Research and Development Institute. 
Lester, P.J. and Greenwood, D.R., 1997. Pretreatment induced thermotolerance in lightbrown apple moth (Lepidoptera: Tortricidae) and associated induction of heat shock protein synthesis. J. Econ. Ent. 90: 199-204.

Neven, L.G., 1998. Effects of heating rate on the mortality of fifth instar codling moth (Lepidoptera: Tortricidae). J. Econ. Ent. 91: 297-301.

Neven, L.G., Rehfield, L.M. and Shellie K.C., 1996. Moist and vapour forced air treatments of apples and pears: effects on the mortality of fifth instar codling moth (Lepidoptera: Tortricidae). J. Econ. Ent. 89: 700-704.

Preisler, H.K. and Robertson, J.L., 1989. Analysis of time-mortality data.J. Econ. Ent. 82: $1534-1542$.

Singh, P., 1983. A general purpose laboratory diet mixture for rearing insects. Insect. Sci. Appl. 4: 357-362

Waddell, B.C. , Clare, G.K., Petry, R.J., Maindonald, J.H., Purea, M., Wigmore, W., Joseph, P., Fullerton, R.A., Batchelor, T.A. and Lay-Yee, M., 1997. Quarantine heat treatment for Bactrocera melanotus (Coquillet) and B. xanthodes (Broun) (Diptera: Tephritidae) in Waimanalo papaya in the Cook Islands. In: A. J. Allwood and R. A. Drew (Eds). Management of Fruit Flies in the Pacific. Proceedings of a Regional Symposium, Nadi, Fiji, 28-31 October 1996. ACIAR Proceedings No. 76. Australian Centre for International Agricultural Research. Canberra, Australia.

Whiting, D.C. and Hoy, L.E., 1998. Effect of temperature establishment time on the mortality of Epiphyas postvittana (Lepidoptera: Tortricidae) larvae exposed to a high temperature controlled atmosphere. J. Econ. Ent. 91: 287-292

Yocum, G.D. and Denlinger, D.L., 1994. Anoxia blocks thermotolerance and the induction of rapid cold hardening in the flesh fly, Sarcophaga crassipalpis. Physiol. Ent. 19: 152-158

Yokoyama, V.Y., and Miller, G.T., 1987. High temperature for control of oriental fruit moth (Lepidoptera: Tortricidae) in stone fruits. J. Econ. Ent. 80: 641-645. 